\title{
Bringing the Tangible into the Virtual: Preserving human-silkworm collaboration
}

\author{
Eugenia S. Kim \\ School of Creative Media \\ City University of Hong Kong \\ eugenia.kim@my.cityu.edu.hk
}

\author{
Feixuan $\mathrm{Xu}$ \\ School of Creative Media \\ City University of Hong Kong \\ feixuan.xu@my.cityu.edu.hk
}

\begin{abstract}
The connotation of the term 'virtual cultural heritage (VCH)' in Hong Kong (HK) tends to refer to virtual reality experiences that replicate physical sites as a form of digital representation and preservation. This raises the question as to whether there are wider and more creative potentialities that are yet to be explored for $\mathrm{VCH}$ by HK researchers. To address this question, the authors use Chinese bio-artist Liang Shaoji's collaboration with silkworms in making sculptural installations as a case study for seeking a more holistic approach to virtualisation that both preserves and presents their trans-species practice. Additional benefits include increased accessibility and dissemination for an ever-changing experience, which would help artist and viewers alike. The particular challenges brought by Liang and the silkworms' art projects lie in two main factors: the ephemeral and meditative ambience dedicated to Daoist philosophical concepts and the erratic and growing traits of some artworks along the time. In regard to the latter trait, certain works constantly change materially and biologically, such as the yellowing process of the silk spun or the lifespan of the species itself including cocooning, egging and urinating. On the other hand, the audience's on-site space-specific and multi-sensuous experiences with the art projects, such as changes in the works' appearance depending on viewer interactions and sensations beyond vision and hearing, are also an integral part of viewing this artistic transformation of a cultural heritage practice that is worth translating into a virtual context. We use a combination of data curation, archival science and digital humanities strategies to propose a model that can be used for Liang's art practice. One author is an anthropologist working directly with Liang; the other is a hybrid artist-archivist-technologist. Through this analysis, the authors plan to apply the resulting process for proposing a VCH experience based on Liang's work to other bio-artists incorporating Asian religious or philosophical ideas. This paper focuses mainly on the analysis and design required to create such a virtual framework and considerations that should be made for the unique needs of such artists.
\end{abstract}

Virtual cultural heritage. Digital humanities. Preservation. Sericulture. Bio-art. Eco-art.

\section{INTRODUCTION}

"Eluding touch, eluding sight. There are their semblances, all right. Profound it is, dark and obscure (惚兮恍兮，其中有象; 恍兮惚兮，其中有 物)".

This sentence from the Tao Te Ching has inspired the theme of Chinese artist Liang Shaoji's recent exhibition 'Huang' (恍) at MWoods Museum in Beijing in 2018. The concept of 'Huang' carries multiple connotations of 'suddenly', 'seemingly', 'ecstasy' and 'absentminded', and artworks displayed in this exhibition manifest Liang's experience and meditation on time, life and ephemerality through his long-term collaboration with silkworms.

The challenges of representing and preserving Liang's art projects can be situated in a broader category of bio-artworks, in which non-human species, growing processes, mutable materials, spiritual articulation and cosmological frameworks are tactically embedded. Turning life, or bioengineered life forms into art, on the one hand, forces the audience to rethink the boundaries of physicality and the established dichotomy of 'natural' and 'artificial', and on the other hand, gives an alert to the easily-accepted exemption from bioartists' ethical responsibility out of scientism or aestheticism (Vaage 2016). 
Concerning the virtualisation of this genre of art practices, would the ethical considerations of creating, caring and disposing of life forms be complicated or dissolved, when material, selfcontained and biophysical 'objects' were transformed into virtual reality? Would the changes in the artworks' tangibility violate or modify the artist's genuine (Daoism-imbued) introspection of instantaneity and eternity expressed via those silkbound installations co-created with silkworms?

Using Liang Shaoji as a case study, we examine these challenges in the context of access and preservation needs where virtualisation is a potential solution to capturing changes in a viewing experience over time. Data curation, archival science and digital humanities principles are applied to analyse how best to preserve this experience at multiple levels with multimedia art used for representation purposes. Although the proposed output is not necessarily unusual in format, it is a challenge in terms of archival processing in that the purpose is not to preserve and present a single instance of content but rather the changes across multiple instances.

\section{BACKGROUND}

\section{1 Eco-art}

Ecological art (or eco-art) as a broad category involves contemporary art projects tackling environmental issues namely climate change, mass extinction, energy and resources, biosystem and sustainability etc., via genres such as paintings, video, sculpture, performance, social-engaged practice, digital art and design (Weintraub 2012). Pioneering works of this movement in the 1960s intended to restore the fragile ecologies to their pre-industrial state, while in the 1970s, cybernetic discourse became dominant and the natural environment was vastly represented as a cyclic 'system' (Demos 2016). More diverse artistic paths in recent decades have shifted to deal with the politics of ecology, multi-species cohabitation and more metaphysically, other-than-human agencies.

Among those tactical responses to the current planetary ecological predicament and Anthropocentric paradigms permeated in most dimensions of human lives, a subcategory of ecoartists identifying as "bio-artists" try to "[reclaim] the skills associated with engaging in direct interactions with the earth's mineral, manufactured and organic matters' (Weintraub 2012). Their attempts echo the trend of posthuman and vital materialist theories, which creatively re-imagine the web of sociality in biopolitics and trans-species communication (e.g. Latour 2017, Haraway 2008, Bennett 2010). Living or semi-living plants, animals, microbes and even cells and genes have been invited into the scene of contemporary art. Their roles become more participatory or autonomous, rather than passively engineered or displayed as metaphor conveyor, raw materials, visual prototypes or mirrors of human sociality (Kirksey and Helmreich 2010). Bioartists sculpt or mould uncanny living entities by using the processes of life, the developments of a micro-organism and the evolution of species (Stracey 2009) and notable examples would be heralds in the 1970s such as Joseph Beuys and Hans Haacke who transported dogs or herbs alive into gallery space, and the more recent stunning green fluorescent protein (GFP) bunny 'Alba' modified genetically by bio-artist Eduardo Kac in 2000.

East-Asian bio-artists, too, have their particular rhetorical strategies, visual construction, conceptual manoeuvre and affective experience with non-human beings. Exemplary practices include the sculptures co-created by bees and Ren $\mathrm{Ri}$, and Liang Shaoji's thirty-year cooperation with silkworms in making installations. Those culturally, ethnically or religiously specific approaches in ecobio-art situated in non-Western milieu might initiate productive dialogues globally on re-imagining life, animism, alternative intelligence, nature and symbiosis. Here lie the double difficulties in the accessibility, preservation and dissemination of these art projects: the mutable organic or inorganic materials displayed physically, and the spiritual or cosmological auras penetrated in the art-creating processes.

\subsection{Cultural Heritage and Virtual Technology}

According to the United Nations Educational, Scientific and Cultural Organization (UNESCO), the term "cultural heritage" can be categorised as "tangible" or "intangible" (UNESCO 2019). For the tangible, items can be objects as of a monumental scale or location-based (UNESCO 1972) while the intangible can include "knowledge and practices concerning nature and the universe or the knowledge and skills to produce traditional crafts" (UNESCO 2011). They further define "digital heritage" as using digital media content and technology such as "texts, databases, still and moving images, audio, graphics, software and web pages" to preserve cultural heritage (UNESCO 2003). It should be noted that content may be born digital or digitised. Using these base definitions as a foundation, it could then be argued that virtual cultural heritage $(\mathrm{VCH})$ is an extension of or categorisable under "digital heritage" with an emphasis on immersive visualisation using mixed reality technology.

Underlying the technology used to create $\mathrm{VCH}$, however, are fundamental concepts found in 
archival science, digital curation and digital humanities. In recent times, increasing numbers of digital humanities and scholarship centres have included AR/VR in their areas of interest. Specific examples include the Duke Digital Humanities Initiative, the Virtual MLK Project, Future Memory Foundation, and the Humanities Virtual Worlds Consortium (Duke University 2017, North Carolina State University Libraries \& College of Humanities and Social Sciences 2017, Future Memory Foundation 2018, University of California Los Angeles Experiential Technologies Center 2017). Frameworks such as the Cultural Heritage Data Reuse Charter make it clear that the preservation of physical and digital cultural heritage collections and objects are essential for all parties involved not just libraries and archives (DARIAH-EU 2017). Although this is just one example of how an ongoing discussion about digital preservation was addressed, such results do not always reach researchers and non-researchers alike. To summarise, if $\mathrm{VCH}$ attracts individuals from various background, then the practices from all these areas contribute to the end product.

\subsection{Examples of $\mathrm{VCH}$ in HK}

For examples of $\mathrm{VCH}$ projects in HK, we mainly looked at museum and academic institutional settings. Two significant examples are projects that were funded by the University Grants Committee, which is under the HK government.

The first example is the Pure Land augmented reality $(A R)$ project created by Prof. Jeffrey Shaw of the School of Creative Media (SCM) in conjunction with collaborators Prof. Sarah Kenderdine (University of New South Wales Art and Design) and Dr Leith Chan (University of Hong Kong). Pure Land was a reproduction of Buddhist paintings found inside a cave of the Dunhuang grotto and debuted in 2012 in HK with subsequent showings around the world through 2016 (Shaw 2017). It was intended to give access to and preserve an endangered cultural heritage site (Kenderdine, Chan \& Shaw 2014). Given that Pure Land is mentioned as a case study in several digital media and humanities texts (Dewdney \& Ride 2013, Schreibman, Siemans, \& Unsworth 2016), it would be reasonable to say that it was a highly successful project for $\mathrm{HK}$ in terms of international reach. The digitisation and preservation plans for the resultant digital objects were not immediately clear.

The other significant example is the Digital Ritual Archive of Chinese Temples in Hong Kong led by Prof. Chi-tim Lai of Chinese University of Hong Kong. In contrast with the Pure land example, this project uses 360-degree video to record the performance of rituals and text readings as part of the Daoist Digital Museum (DDM) (Lai 2016). As it was only recently started in 2017 and has not reached completion at the time of writing, it is hard to determine what the final output will look like. One distinguishing feature is the use of GIS data to accompany multimedia features. A preview of the expected experience can be seen on the DDM website (Daoist Digital Museum 2016). Neither the project description nor the website explains how archival or preservation principles are followed.

\section{LIANG SHAOJI - CASE STUDY ANALYSIS}

Liang Shaoji is a Chinese bio-artist born in 1945 and has lived with and worked with silkworms since 1988 to create artworks. Silkworms being his companion species and collaborators, have been invited by the artist to spin on diverse objects including daily stuff such as smoke case, paper, electric wires, and large objects such as bamboos, woods, and blocks. Though the Chinese character of silkworm (虫, can) accidentally share very similar pronunciation of the character of Zen (禅, chan), the artist deliberately cooperates with this species and crafts his understanding of time, life, eternality and reincarnation inspired by Chinese Daoist worldview and wisdom. The spiritual and spatiotemporal planes embedded his art practice bring certain challenges to the preservation and presentation strategies using mixed reality technologies.

As for the time scale, silk as a natural protein fibre yellows gradually on the one hand, and on the other hand silkworm goes through four stages of growth as egg, larva, pupa and moth within six to eight weeks. The installation Time and Permanence (1993-2018), for example, is an ongoing piece of work where silkworms spin on the previous layers of silk and along the years the inner parts of the fibre become yellowish and greyish and the new layers on the surface are relatively white and shimmering. 


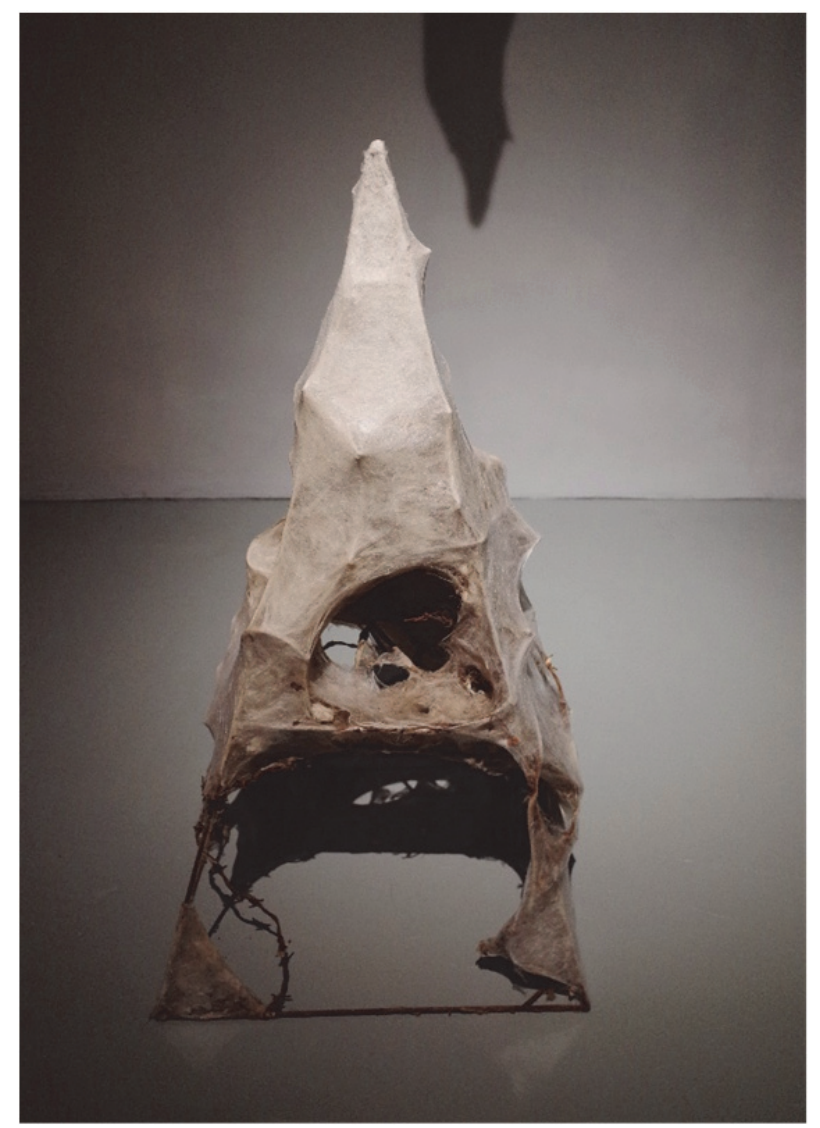

Figure 1: Time and Permanence (1993-2018). Picture courtesy of Feixuan Xu.

Also, in Dream of Yarn (2016), the span of silkworms' whole life is spent and recorded on a large piece of silk cloth, including spinning, excreting, cocooning and spawning. While spinning, silkworms disperse their faeces and urine among the cloth whose physical traces are kept in their original forms on the textile. The mutating and erratic processes of organic and non-organic matters in these two works are as vital as the 'final' appearance being shown in an art exhibition but are seldom accessible to the audience and researchers.

In regard to space, when the set of silk-covered pyramidal installations called The Temple (20132018) were exhibited at MWoods Museum, the gallery hall with a four-meter-high ceiling was designed to create a celestial and ethereal effect. The shadows of those iron-silk installations placed on the ground were reflected on the dark ceil, resembling the temple-like sublime and tranquillity.

In the same exhibition, Planar Tunnel (2011-2012) is also displayed on the white wall, where the extremely thin and light silk pieces can reflect jadelike or metal-like sheen under different light sources and the shadows on the wall overlap with the silk plane to duplicate their delicate textures. If a viewer walks close enough, even the breath can blow the silk planes into a tremble.

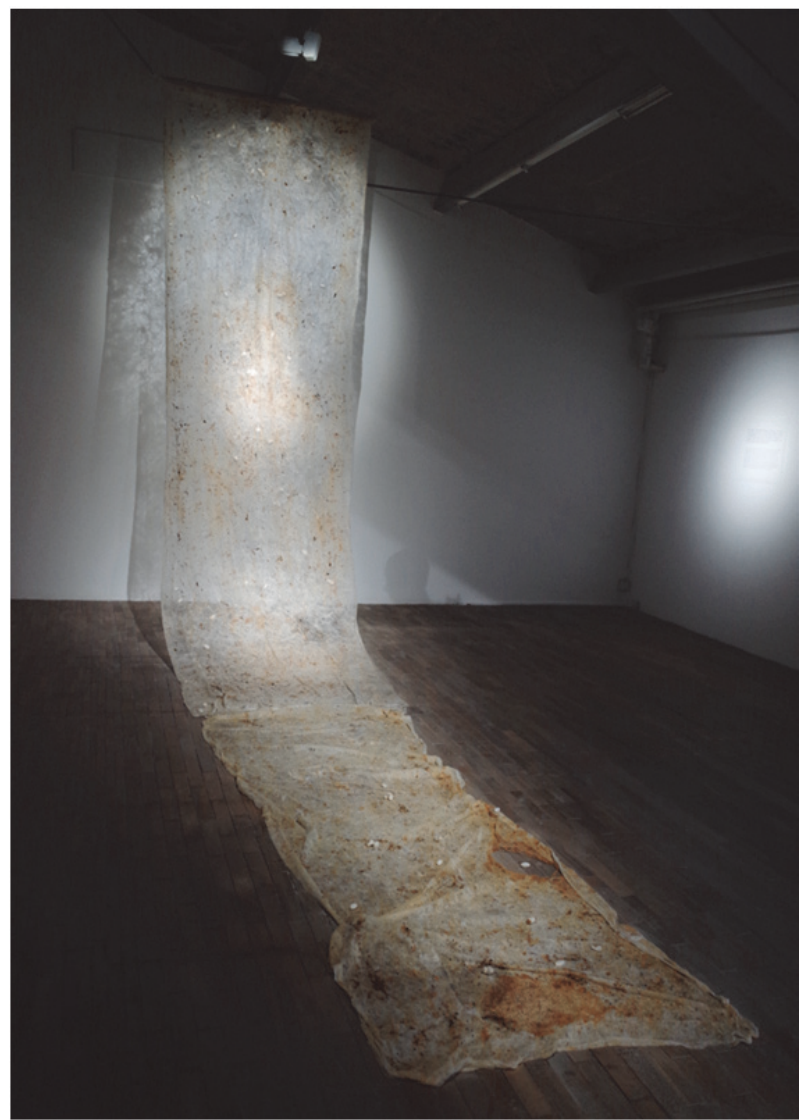

Figure 2: Dream of Yarn (2016). Picture courtesy of Feixuan Xu.

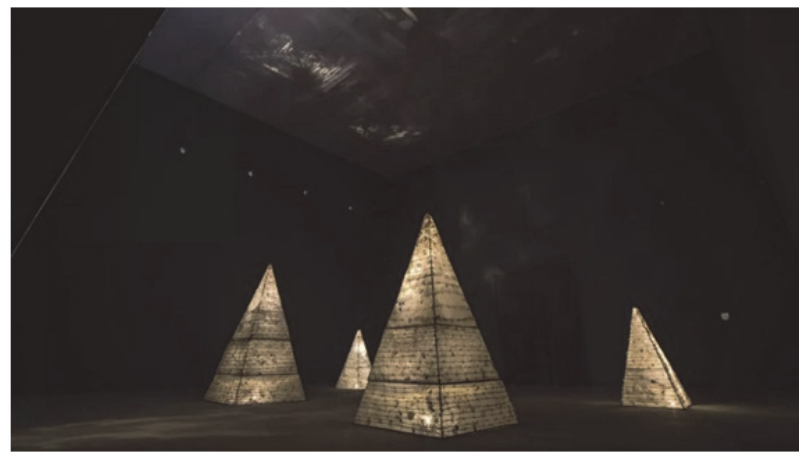

Figure 3: The Temple (2013-2018). Picture courtesy of the MWoods Museum.

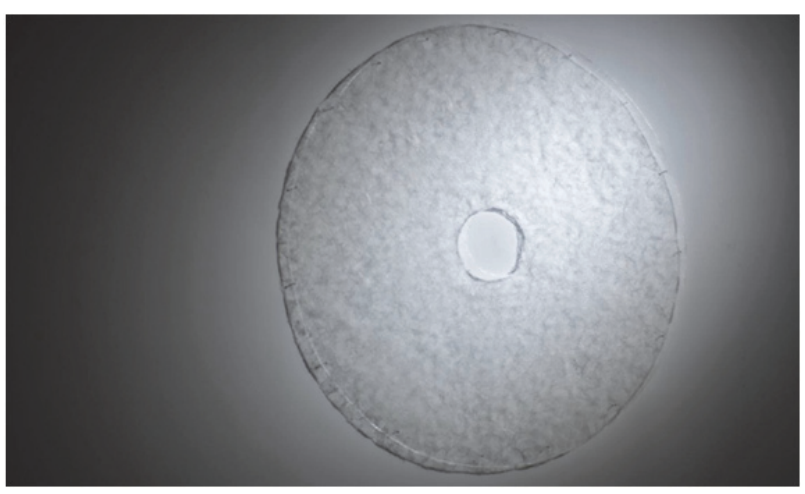

Figure 4: Planar Tunnel (2016). Picture courtesy of Feixuan Xu. 
In another performative project named Cloud Mirror (2007), the silkworms spin on a piece of mirror and this silk-mirror assemblage was placed by the artist on the peak of Tian Tai Mountain (with a Daoist temple located there) to welcome the clouds' reflection onto the mirror. The artist himself sat by and meditated surrounded by the mountains, sky, cloud, daylight and the installation. Both the artist and the audience's on-site physical and psychological experience in the mentioned scenes are triggered and contextualised by carefully arranged space. How and to what extent the multisensuous and empathetic engagement with bioorganic materials in the subtle ambience can virtually recur is a big challenge.

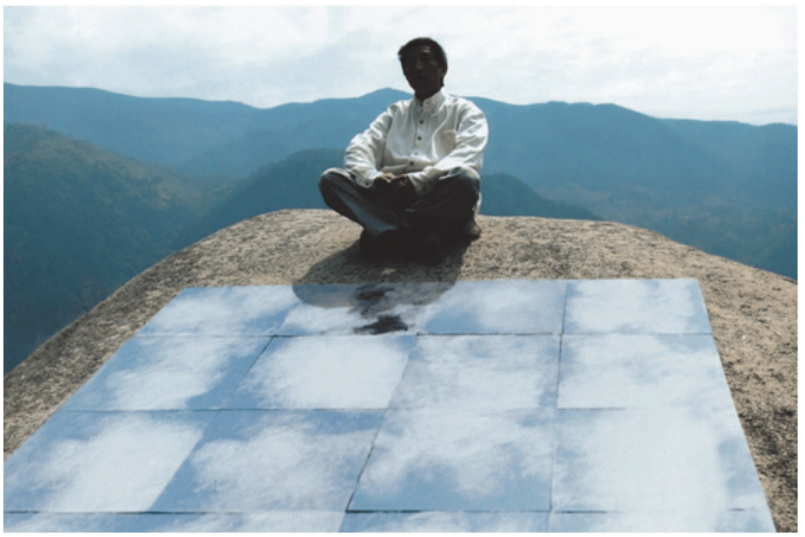

Figure 5: Cloud Mirror (2007). Picture courtesy of Liang Shaoji.

\section{RESPONSE TO CASE STUDY ANALYSIS}

The primary reason why we believe that Liang's work falls under the definitions of "cultural heritage" is that sericulture is an intangible cultural heritage practice that spreads across continents from China. When translated through his artistic practices, this practice becomes too complex to simply preserve through an image database or textual descriptions. Thus, virtualisation is an ideal way for capturing the motion found in and various instantiations of his work, much the way one might try to capture a performance or durational event.

In order to come up with an access and preservation proposal for Liang, we used methods and principles from the data curation and digital humanities communities as a foundation. The goals of "access" and "preservation" were redefined somewhat from the terms found in those communities to reflect the nature of the content. For "access", the purpose was to make available a viewing experience rather than simply digitised content. Likewise, "preservation" referred to not only the content and its contextual information such as metadata, but also the experience over time of viewing Liang's works. Furthermore, in creating a $\mathrm{VCH}$ solution, one generates digital objects that are a derivative artwork that requires its own digital preservation solution. By using Liang's situation as a case study, we intend to create a proposal plan that could be used for similar bio-artists.

At the root of this process are archival science and data curation processes. In terms of content, even though the specific artworks to be replicated have been narrowed down, it is now necessary to assess and select which elements of the original artwork and documentation will best inform the virtual recreation of an experience. It is also essential to interview the artist to find what they consider essential in the representation of their work. One source of inspiration is the Artist's Legacy Toolkit (Dance Heritage Coalition 2013), which was originally meant for dance archival collections. It provides a template for arranging, preserving and sharing a collection with an emphasis on using repository-based services. To get more information about a creator's intention and a more digital perspective, a tool such as the Data Curation Profiles Toolkit (DCP) provides a template for asking useful questions as well as assessing any existing digital files (Data Curation Profiles 2019). Since this tool was originally designed for academic researchers, some modification is obviously necessary. As the DCP was designed to be customisable, this does not present a problem. The value in combining elements from both types of toolkits is that inasmuch as the process is about preserving artwork, there are also biological elements that are usually found more frequently in scientific research. So it is not as simple as saying "This is an artistic/cultural collection" or "There are living organisms with DNA and other biological matter to preserve."

The next step is to ensure that the artworks and contextual information being digitised have gone through some form of processing and arrangement if it has not already been completed. After that, any digital objects themselves will require preservation and then finally, the virtual representation will also need a preservation plan. In this case, because the digitised content will be combined to form a new entity, the new entity's own preservation is essential.

Once a profile of Liang's process and needs have been generated as well as the content to be reproduced, the digitisation process can be undertaken. As seen in the case study description, there were five works deemed to be representative of his overall practice. For the digitisation process, we deviated from a typical practice of choosing a common output format for all the examples and first looked at how each work might be represented in the virtual realm: 
- Time and Permanence: An animation starting with the work in its original state, then going through the yellowing stages. The user would be able to go forwards and backwards through the stages with a timeline of key milestones for reference.

- Dream of Yarn: A time-lapse animation/video of the process with a timeline of key milestones for reference.

- The Temple: A 360-degree video or a 3D reproduction of the space with changing shadows

- Planar Tunnel: Similar to The Temple with the option to make the wind blow.

- Cloud Mirror: A virtual representation of the mountain, spinning worms and Liang accompanied by the artist's commentary.

Rather than simply recreate the experience of viewing a single work or creating a virtual museum, the goal of this collection of experiences is to show the intangible elements mentioned in the case study.

Based on the above, it is reasonable to assume that photography, videography and $3 D$ scanning is required to either capture the works as they are or reproduce them using 3D modelling software. The digital output to be saved would be in the form of TIFF, MP4 and OBJ. Later on, 3D animations would likely be saved in FBX format to import into a program like Unity. Finally, as we would likely be using Unity for creating the virtual experience, all of those project files would need to be maintained as well. If a truly barebones option was the only choice, then a series of 360-degree videos made available through a website could be produced and viewed that way or via phone. At the highest end, users would get an immersive experience using a $6 \mathrm{D}$ headset.

To summarise, a proposed course of action for Liang would contain the following:

(i) Profile - an outline of the artist's intent and needs in order to preserve their work while making it accessible.

(ii) Digitisation Overview - the methods and file formats needed to digitise any physical objects as well as anticipated costs based on location and other factors.

(iii) Virtualisation Overview - descriptions and mock-ups of each artwork to be virtualised as well as the components required (i.e. animation, metadata, audio, etc.). Anticipated costs would be based on location and other factors.

(iv) Preservation Overview - recommended practices for preserving the physical artworks (if necessary), the digital objects, and the virtual experience. This includes storage and maintenance recommendations until a suitable long-term solution can be identified (if one is not already found).

\section{NEXT STEPS AND FUTURE VISION}

As contemporary bio-artists attempt to challenge the conceptual categories of nature, material, and life etc., their artworks are often featured with growing process, uncanny agency and peculiar intimacy with human lives. In exhibition and preservation contexts, conventional art objects serve as the portal of narratives or carriers of thoughts, with physically distinctive boundaries or borders from other entities, while bio-eco-art is pushing the borderlines of object into 'hyperobject' that requires new vision and means of human beings to appreciate and approach. The term 'hyperobject' is originally proposed by ecological philosopher Timothy Morton to indicate the massively distributed and compounded climate change, global warming and radioactive contamination etc. in the era of ecocide, being beyond the full perception of human but still having huge impacts (2007). In regard to the virtualisation of bio-art, the tangible objects, similarly, are transformed into radical hyperobjects in the virtual realm, where the 'singular' instantaneity are multiplied, extended, lasted and complicated by virtue of more diverse means of access and fewer limits in spatiotemporal senses.

A further practical concern on virtualising arts or cultural heritages like Liang's practice would be the possible reduction of ecological footprints in preservation and exhibition. Despite saving the cost of transportation and print dissemination for a traditional on-site exhibition, artworks by Liang that contain DNA require extra costs in transportation and labour, especially across national borders. Living silkworms and the silk they spun in virtual reality, therefore, enjoy more freedom to move and less chance to be disposed of; moreover, their lifespan would be prolonged in an alternative instance with new spatiotemporal scales.

The significance in our approach to this scenario is that we are attempting to bridge a gap between archival science, artists, and multimedia technology communities. As of 2019, the most prominent organisation in $\mathrm{HK}$ for the preservation of contemporary artworks would be the Asia Art Archive. Its main mission is still rooted in art history rather than the utilisation of new technologies which means that there are no $\mathrm{VCH}$ services offered at the time of writing. Other options would include museums and academic institutions, which tend to be focused on exhibition production. This 
leads to a question of what happens to those virtual experiences after they have been shown.

\section{CONCLUSION}

Although the process of creating $\mathrm{VCH}$ experiences has been going on for quite some time, it could be argued that in HK they are still generally oriented towards tangible cultural heritage experiences rather than intangible ones. Nonetheless, the process of creating a VCH project yields new digital objects with added layers of meaning that require preservation as well. From a technical perspective, the problems are simple in that they are a continuation of existing issues within digital preservation. Thus, the real challenge would be to see whether $\mathrm{VCH}$ could go beyond simply replicating an existing experience to being able to evolve an existing experience to a higher level.

From a philosophical perspective, turning bio-art into a $\mathrm{VCH}$ experience raises the question of whether virtualisation contradicts the ethos and practices of that community. In some ways, the intersection of nature and technology would reflect a need for co-existence as neither entity will be entirely abandoned nor adopted. Another way of looking at virtualisation, or digitisation of any kind, is that it leads to just another instance of existence. When viewed that way, the digital realm can give new life to not only monuments and other sites, but to actual life-forms as well. For beings as ephemeral and short-lived as silkworms, virtualisation may lead to their reincarnation and immortality.

\section{REFERENCES}

Bennett, J. (2010) Vibrant Matter: A Political Ecology of Things. Duke University Press, Durham.

Daoist Digital Museum (2016)

http://dao.crs.cuhk.edu.hk/digitalmuseum/CH/ (retrieved 16 March 2019).

Data Curation Profiles. Data Curation Profiles: Overview. http://www.datacurationprofiles.org (retrieved 16 March 2019).

DARIAH-EU (2017) Heritage Data Reuse Charter. https://www.dariah.eu/tools-services/data-re-use/ (retrieved 16 March 2019).

Demos, T. J. (2016) Decolonizing Nature: Contemporary Art and the Politics of Ecology. Sternberg Press, Berlin.

Dewdney, A. and Ride, P. (2014) The Digital Media Handbook. Routledge, London.

Duke University (2017) Duke Digital Humanities Initiative. https://digitalhumanities.duke.edu/vardhi (retrieved 16 March 2019).
Future Memory Foundation. (2018) The Times of Israel: At Westerbork, virtual reality simulations. http://www.futurememoryfoundation.org/?p=216 (retrieved 16 March 2019).

Haraway, D. J. (2008) When Species Meet. University of Minnesota Press, Minneapolis.

Kenderdine, S., Chan, L. K., and Shaw, J. (2014) Pure Land: Futures for Embodied Museography. Journal on Computing and Cultural Heritage, 7(2), pp.1-15.

Kirksey, S.E., and Helmreich, S. (2010) The Emergence of Multispecies Ethnography, Cultural Anthropology, 25(4), pp.545-576.

Lai, C. (2016) General Research Fund 14652616: Digital Ritual Archive of Chinese Temples in Hong Kong: Study of Multi-dimensional Ritual Processes.

https://cerg1.ugc.edu.hk/cergprod/scrrm00542.jsp? proj id $=14652616 \&$ old proj id $=16191616 \&$ proj tit| $\mathrm{e}=$ \&isname $=$ Lai\&ioname $=$ \&institution $=$ \&subject $=\& \mathrm{p}$ ages $=1$ \&year $=2016 \&$ theSubmit $=14652616$ (retrieved 16 March 2019).

Latour, B. (2017) Facing Gaia: A New Enquiry into Natural Religion. Polity Press, Cambridge.

Morton, T. (2007) Ecology without Nature: Rethinking Environmental Aesthetics. Harvard University Press, Cambridge.

North Carolina State University Libraries and College of Humanities and Social Sciences. (2017) Virtual Martin Luther King, Jr. Project. http://vmlk.chass.ncsu.edu/ (retrieved 16 March 2019).

Schreibman, S., Siemens, R. G., and Unsworth, J. (2016) A New Companion to Digital Humanities. John Wiley \& Sons, Chichester.

Shaw, J. (2017) Pure Land AR. https://www.jeffreyshawcompendium.com/portfolio/ pure-land-arl (retrieved 16 March 2019).

Stracey, F. (2009) Bio-art: The Ethics Behind the Aesthetics, Nature Reviews Molecular Cell Biology, 10(7), pp.496-500.

United Nation Educational, Scientific and Cultural Organization (UNESCO) (1972) Convention Concerning the Protection of the World Cultural and Natural Heritage.

http://whc.unesco.org/en/conventiontext/ (retrieved 16 March 2019).

United Nation Educational, Scientific and Cultural Organization (UNESCO) (2003) Charter on the Preservation of Digital Heritage.

http://portal.unesco.org/en/ev.phpURL ID=17721\&URL DO=DO TOPIC\&URL SEC TION=201.html (retrieved 16 March 2019). 
United Nation Educational, Scientific and Cultural Organization (UNESCO) (2011) What is Intangible Cultural Heritage? https://ich.unesco.org/en/whatis-intangible-heritage-00003 (retrieved 16 March 2019).

United Nation Educational, Scientific and Cultural Organization (UNESCO) (2019) Illicit Trafficking of Cultural Property.

http://www.unesco.org/new/en/culture/themes/illicittrafficking-of-cultural-property/unesco-database-ofnational-cultural-heritage-laws/frequently-askedquestions/definition-of-the-cultural-heritage/ (retrieved 16 March 2019).
University of California Los Angeles Experiential Technologies Center (2017) Humanities Virtual Worlds Consortium.

http://virtualworlds.etc.ucla.edu/ (retrieved 16 March 2019).

Vaage, N.S. (2016) What Ethics for Bioart? NanoEthics, 10(1), pp.87-104.

Weintraub, L. (2012) To Life!: Eco Art in Pursuit of a Sustainable Planet. University of California Press, Ewing. 